\title{
The Effect Analysis of Rudder between X-Form and Cross-Form
}

\author{
HAN Zhao-Lin ${ }^{1, ~ a, ~ Z H A N G ~ Z h o n g-Z h e n g ~}{ }^{2, b}$, WANG Long- Jin ${ }^{3, c}$ \\ 1,2,3 College of Electromechanical Engineering, Qingdao University of Science and Technology, \\ China

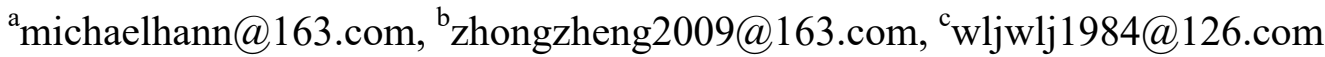

Keywords: Cross-form rudder, X-form rudder, Simulation, Contrast

\begin{abstract}
According to existing submarine model with cross-form rudder, achieving the model transformation from cross-form rudder to X-form rudder combining with the submarine maneuverability principle. This article mainly analyzes the rudder effects of control surface between the former cross-form rudder and the later X-form rudder, which shows the advantages of X-form rudder. Finally using the Matlab software to simulate the rudder effects so that could verify this assumption.
\end{abstract}

\section{Introduction}

After the First World War, the submarine has been used widely, which play a dominant role in navy equipment in many countries. The stern and control surface of modern submarines are almost arranged as sharp stern and single propeller. The basic form of control surface is cross-form rudder and $\mathrm{X}$-form rudder ${ }^{[1]}$, and on the basis of that, there are some different rudder types, such as differential cross-form rudder, $\mathrm{H}$-form rudder, and low rudder ${ }^{[2]}$. The stern rudder of submarine which has the assistant wings is still at the experimental research about its principle, and which will also be applied to submarine control ${ }^{[3]}$.

In the last century, cross-form rudder submarine was always as the basic form of modern submarine. This is mainly because cross control surface is symmetrical, the horizontal rudder and vertical rudder are orthogonal, and the area is approximately equal. Besides, the horizontal rudder and vertical rudder are more convenient for pilot to control submarine directly. X-form rudder is a separate stern rudder which refers to the four stern rudders are arranged as X-form with orthogonal layout and the rudder axes is at an angle with the submarine central longitudinal section (the angle is usually at 45). Compared with the cross rudder, $\mathrm{X}$-form rudder has the following advantages:

Firstly, X-form rudder has the higher rudder efficiency and its manipulate surface area is smaller about $10 \%$ than cross rudder, so that submarine could avoid the collision problem when it is landing. Secondly, X-form rudder reduces the serious consequences by rudder-blocked and improves the security and the underwater dynamic unsinkability. Besides, X-form rudder reduces the heeling moment, weight and stern heaviness when cross-rudder submarine turning, and having an advantage 
to sail steadily when it is attacked. Finally, X-form rudder reduces interaction between propeller and rudder, and reduces the noise ${ }^{[4]}$.

\section{The model of two type rudders}

Cross-form rudder control surface has two rudder blades, which appears orthogonal with the horizontal and vertical, and X-form rudder control surface consists of four rudder blades, which are distributed with the X-from, just as shown in figure 1. Cross-form rudder blades has two sets of control system, which consist of the horizontal control system and the elevator control system. And the X-form rudder blades need 4 sets of control system respectively ${ }^{[5]}$.

Submarine cross-form rudder blades are named as the rudder and the elevator, which corresponding rudder Angle are $\delta_{r}$ and $\delta_{s}$, and comparing with cross-form rudder, X-form rudder blades are named as Num. 1 rudder, Num.2 rudder, Num.3 rudder and Num.4 rudder, which corresponding rudder Angle are $\delta_{1}, \delta_{2}, \delta_{3}$ and $\delta_{4}$.

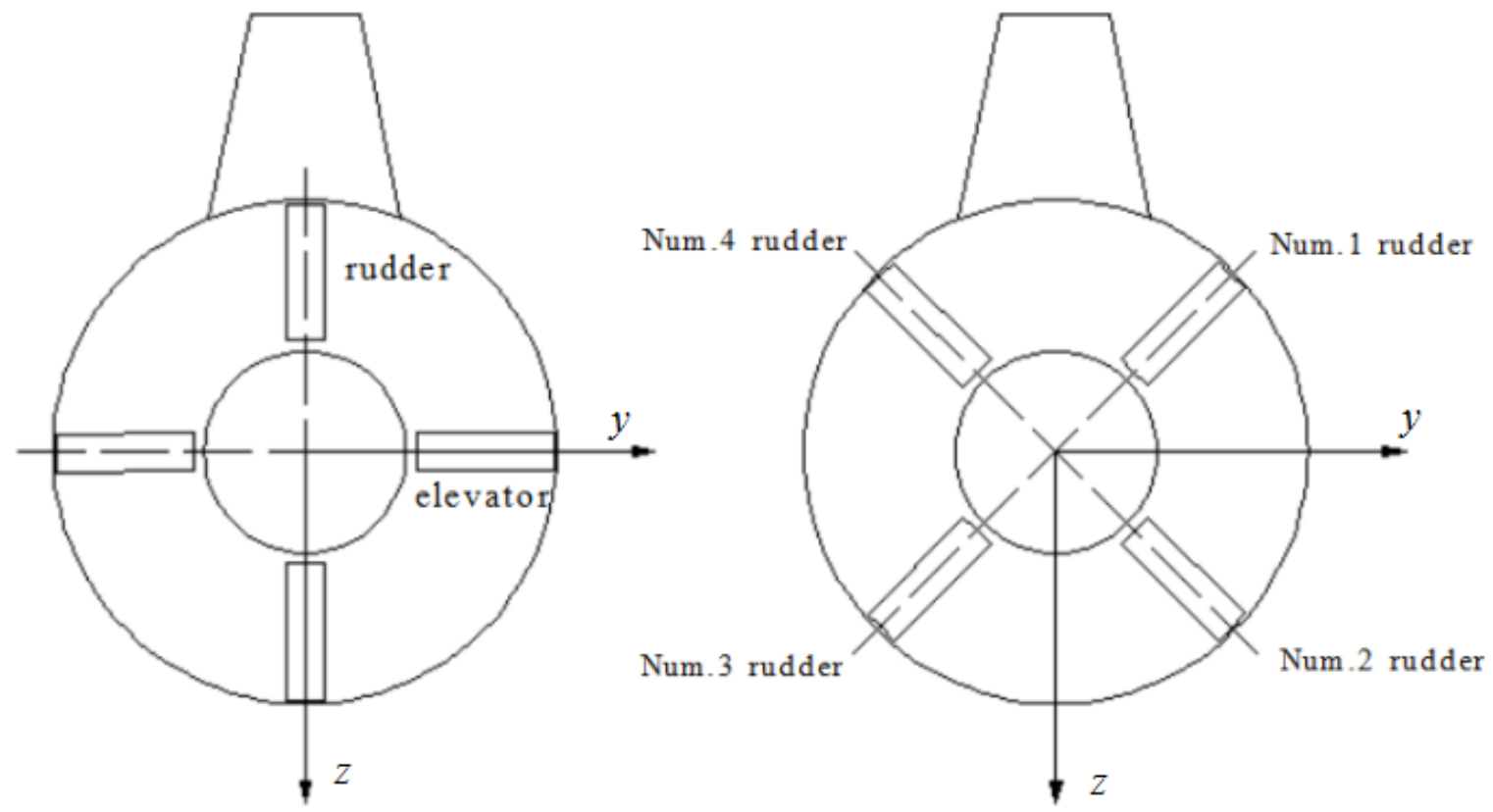

Fig.1 The control surface of two types rudder

Firstly establishing submarine coordinate system in cross-form rudder control surfaces, among that, the $\mathrm{y}$ axis points to the starboard side of the submarine, the $\mathrm{z}$ axis points to the center of the earth. In order to analyze expediently, we might have cross-form rudder force is proportional to the corresponding rudder Angle, namely the rudder steering force (torque) is proportional to the rudder Angler, and the elevator force (torque) is proportional to the elevator Angle. Setting the coefficient of cross-form rudder effect as $Y_{\delta r}$ and $Z_{\delta s}$, get the force (torque) formula expressions of cross-form rudder :

$$
\left\{\begin{array}{l}
\vec{F}_{\mathrm{y}}=\left(Y_{\delta_{\mathrm{r}}} \delta_{r}, 0\right) \\
\vec{F}_{z}=\left(0, Z_{\delta_{s}} \delta_{s}\right)
\end{array}\right.
$$

In the same way, establishing submarine coordinate system in X-form rudder control surfaces, Each rudder blade of $\mathrm{X}$-form rudder control is at an angle of $45^{\circ}$ with longitudinal or vertical surface. 
Therefore, a blade could produce a space force and a torque, unlike the cross-form rudder which makes a single force. For the rudder force (torque) effect of X-form rudder, represented in table 1:

Table 1 The effects of X-form rudder control surface

\begin{tabular}{c|c|c}
\hline Rudder Angle $\delta_{i}$ & Plus Or Minus & Movements \\
\hline \multirow{2}{*}{$\delta_{1}$} & $>0$ & Turn right, Diving, Heel left \\
\cline { 2 - 3 } & $<0$ & Turn left, Floating, Heel right \\
\hline \multirow{2}{*}{$\delta_{2}$} & $>0$ & Turn right, Floating, Heel right \\
\cline { 2 - 3 } & $<0$ & Turn left, Diving, Heel left \\
\cline { 2 - 3 }$\delta_{3}$ & $>0$ & Turn right, Diving, Heel right \\
\cline { 2 - 3 } & $<0$ & Turn left, Floating, Heel left \\
\cline { 2 - 3 }$\delta_{4}$ & $>0$ & Turn right, Floating, Heel left \\
\hline
\end{tabular}

We could get the formula expressions of X-form rudder effect:

$$
\left\{\begin{array}{c}
\vec{F}_{1}=\left(Y_{1} \delta_{1} \cos \pi / 4, Y_{1} \delta_{1} \sin \pi / 4\right) \\
\vec{F}_{3}=\left(Y_{3} \delta_{3} \cos \pi / 4, Y_{3} \delta_{3} \sin \pi / 4\right) \\
\vec{F}_{2}=\left(-Z_{2} \delta_{2} \sin \pi / 4, Z_{2} \delta_{2} \cos \pi / 4\right) \\
\vec{F}_{4}=\left(-Z_{4} \delta_{4} \sin \pi / 4, Z_{4} \delta_{4} \cos \pi / 4\right)
\end{array}\right.
$$

Among that, $Y_{1}=Y_{3}=0.5 Y_{r}, Z_{2}=Z_{4}=0.5 Z_{s}$. As the $\delta_{1}=\delta_{3}=\left(-\delta_{2}\right)=\left(-\delta_{4}\right)$ and $\delta_{1}=\delta_{3}=\delta_{2}=\delta_{4}, \mathrm{X}$-form rudder effect in y-axis and z-axis:

$$
\begin{aligned}
& F_{y}=Y_{1} \delta_{1} \cos 45^{\circ}+Y_{3} \delta_{3} \cos 45^{\circ}+Z_{2} \delta_{2} \sin 45^{\circ}+Z_{4} \delta_{4} \sin 45^{\circ}=1.414 Y_{r} \delta_{r} \\
& F_{z}=Y_{1} \delta_{1} \sin 45^{\circ}+Y_{3} \delta_{3} \sin 45^{\circ}+Z_{2} \delta_{2} \cos 45^{\circ}+Z_{4} \delta_{4} \cos 45^{\circ}=1.414 Z_{s} \delta_{s}
\end{aligned}
$$

It is not difficult to find that rudder effect improve obvious when the cross-form rudder equivalently transform $\mathrm{X}$-form rudder.

\section{Simulation and discussion}

Then, use the Matlab to simulate theory mentioned. What is shown in figure 2-a is cross-form rudder control model diagram, the five input in left side are: the rudder angle, elevator Angle, bow rudder Angle, main engine speed, buoy(water volume to balance), and the right in model diagram is output, the Pos 1 is the submarine line that is simulated. As shown in figure 2-b is X-form rudder control model diagram, and seven input are: Num.1 rudder Angle, Num.2 rudder Angle, Num.3 rudder Angle, Num.4 rudder Angle, bow rudder Angle, main engine speed, buoy(water volume to balance). 


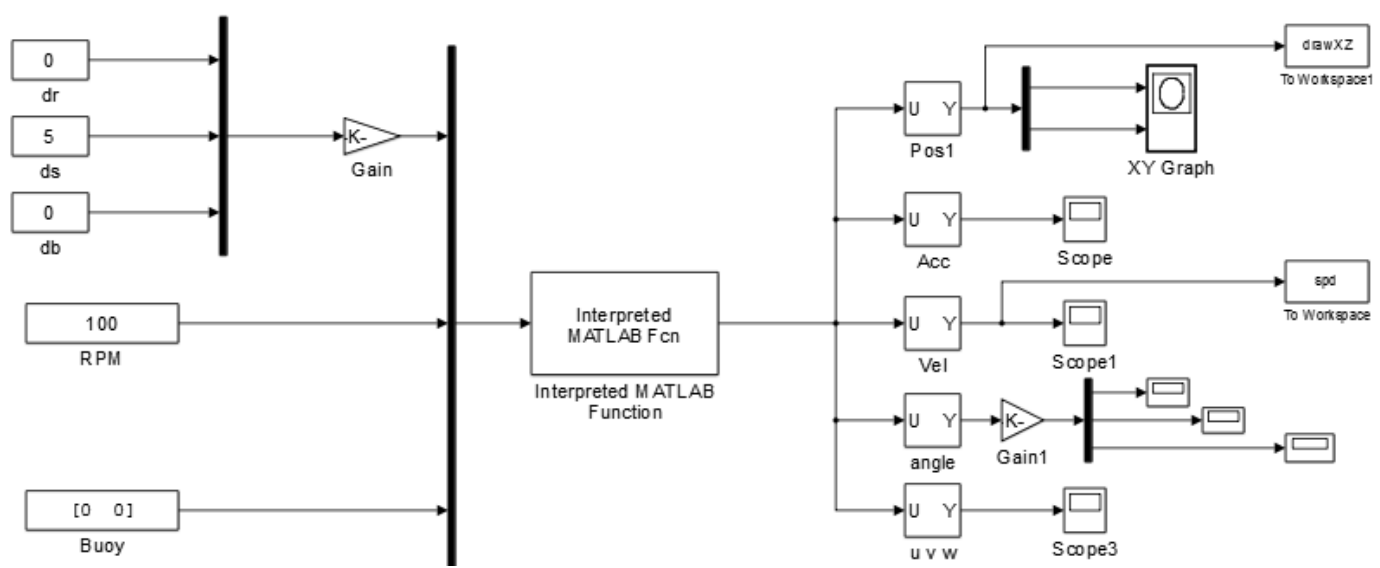

Fig.2-a The control model of cross-form rudder

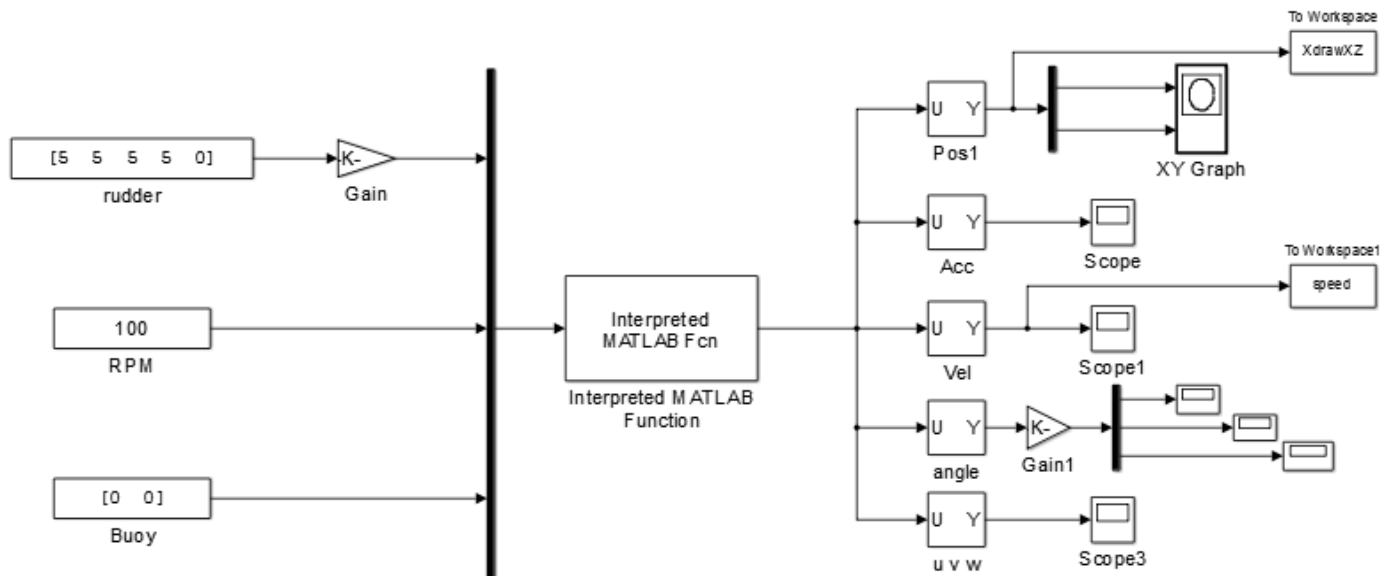

Fig.2-b The control model of X-form rudder

Simulation of rotational movement. As the cross-form rudder model, the rudder Angle $\delta_{r}$ is $10^{\circ}$, elevator rudder Angle $\delta_{s}$ and bow rudder Angle $\delta_{b}$ are zero, the engine speed is 100, and the buoy is 0 , then have the $300 \mathrm{~s}$ movement simulation, so get result in the figure 3-a. Also, as the X-form rudder control surface model, $\delta_{1}=\delta_{3}=10^{\circ}, \delta_{2}=\delta_{4}=\left(-10^{\circ}\right), \delta_{b}=0$, the remaining is same with cross-rudder's, get the simulation in the figure $3-b$.

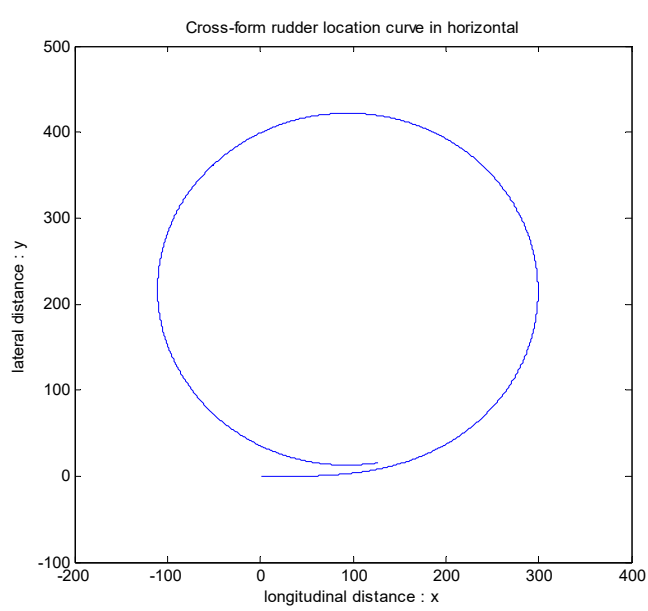

Fig.3-a Rotational movement of cross-form rudder

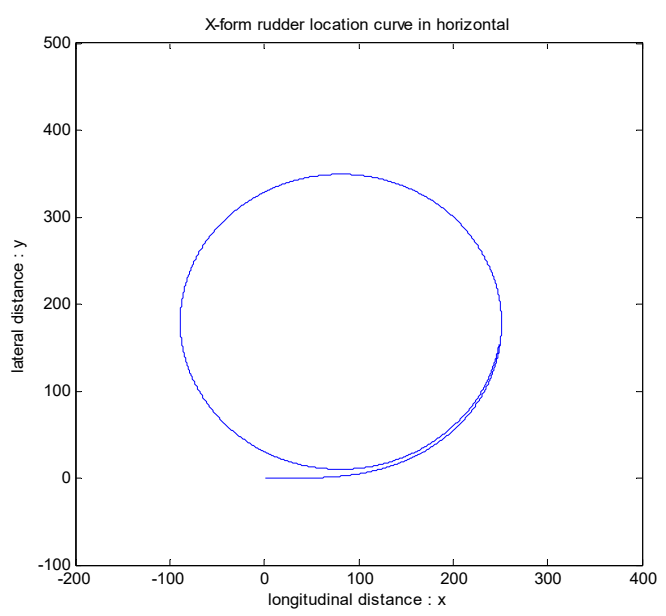

Fig.3-b Rotational movement of X-form rudder 
Stern rudder coefficient(except the rudder Angle) are no different. Through the simulation we can see that cross-form rudder radius of gyration is about 210 meters, and completed the $360^{\circ}$ rotation movement in the 300s. X-form rudder radius of gyration is about 170 meters, and completed the $450^{\circ}$ rotation movement in the $300 \mathrm{~s}$. It is easy to conclude that X-form rudder, compared to cross-form rudder, has smaller radius of gyration, better rotating effect.

Simulation of diving movement. In the cross-form rudder model, the rudder Angle $\delta_{r}$ and bow rudder Angle $\delta_{b}$ are zero, the elevator rudder Angle $\delta_{s}$ is $5^{\circ}$, engine speed is 100 , and the buoy is 0 , then have the $200 \mathrm{~s}$ movement simulation, get the result in figure 4-a. Also, as the X-form rudder control surface model, $\delta_{1}=\delta_{3}=5^{\circ}, \delta_{2}=\delta_{4}=5^{\circ}, \delta_{b}=0$, the rest is same with cross-rudder's, get the simulation in the figure 4-b.

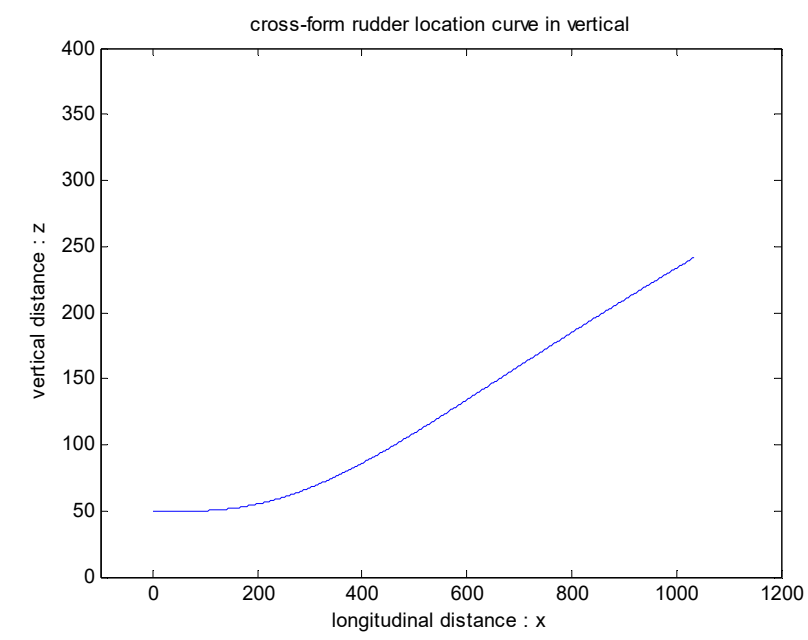

Fig.4-a Diving movement of cross-form rudder

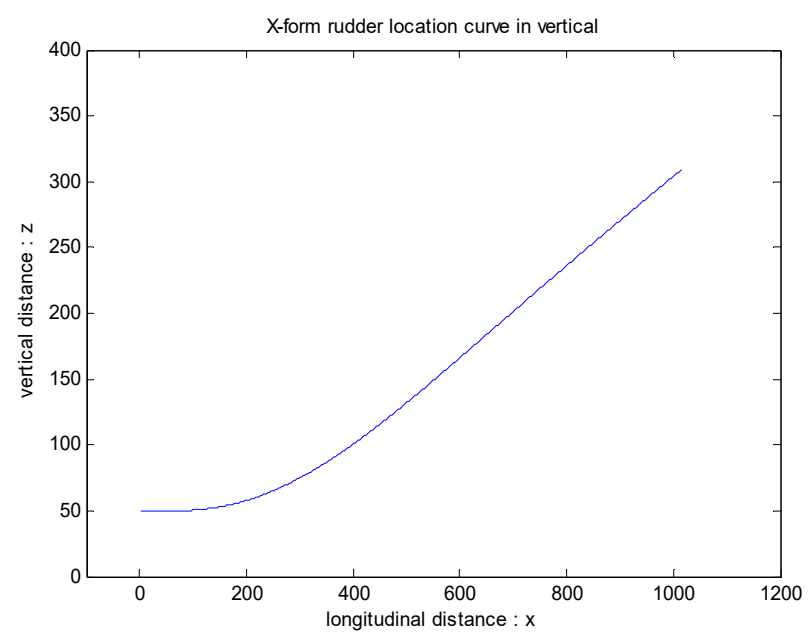

Fig.4-b Diving movement of $\mathrm{X}$-form rudder

Through simulation we can see that in the 200 seconds of diving, cross-form rudder from the original 50 meters underwater dived to the 250 meters underwater, and X-form rudder from 50 meters underwater dived to more than 300 meters underwater. It can be concluded that X-form rudder has better effect than cross-form rudder.

\section{Conclusions}

(1) Two types stern rudder transition is based on the existing cross-form rudder control model, combined with the submarine maneuvering and submarine hydrodynamics principle, established a new control model of X-form rudder. Two types stern rudder only have difference on rudder and rudder Angle after transition.

(2) Analyze the submarine stern rudder control surfaces abstractly, which is concluded that $\mathrm{X}$-form rudder has higher effect than cross-form rudder, that is about 1.414 times.

(3) Through the Matlab simulation, the analysis results was verified, and found that X-form rudder had a smaller radius of gyration. 


\section{Acknowledgements}

This work was financially supported by Qingdao Application Foundation Research Project (14-2-4-116-jch).

\section{References}

[1] Shi Sheng-da. Submarine manoeuvrability [M]. Beijing: National Defend Industry Press, 1995.(in Chinese)

[2] Kurt J H. Automatic Control of a Submersible [D].Miami University.AD-A144790.

[3] T.D. Enguian, S. Gowing, D. Boqinzki. The application in ships' navigation of adjusting shim control surfaces [C]. Sixth international submarine translation corpus. Chinese Ship Scientific Research Center, 2001.(in Chinese)

[4] Li Jie. Submarine stern rudder: select the cross or X [N]. China national defense. 2010.12.7,15.(in Chinese)

[5] Lin Jun-jie, Dai Yu-liang, Zhang Tao. equivalent rudder Angle research of X-form rudder and cross-form rudder control force [J]. Ship \& Ocean Engineering, 2004, (5).(in Chinese) 